\title{
БИЗНЕС-ИНКУБАТОРЫ КАК ЭЛЕМЕНТ ИННОВАЦИОННОЙ ЭКОСИСТЕМЫ: СОВРЕМЕННОЕ СОСТОЯНИЕ И ТЕНДЕНЦИИ (ЧАСТЬ І)
}

\author{
(C) 2018 Хотяшева Ольга Михайловна \\ кандидат экономических наук \\ доцент кафедры менеджмента, маркетинга и ВЭД имени И.Н. Герчиковой \\ научный руководитель магистратуры «Отраслевой маркетинг товаров и услуг» МГИМО \\ директор Бизнес-инкубатора МГИМО \\ директор Фонда развития инноваций и бизнес-инкубаторства» МГИМО \\ Московский государственный институт международных отношений (университет) \\ Министерства иностранных дел Российской Федерации (МГИМО) \\ 119454, г. Москва, проспект Вернадского, 76 \\ (c) 2018 Слесарев Максим Александрович \\ преподаватель кафедры Менеджмента, маркетинга и ВЭД имени И.Н. Герчиковой \\ заместитель директора Бизнес-инкубатора МГИМО \\ Московский государственный институт международных отношений (университет) \\ Министерства иностранных дел Российской Федерации (МГИМО) \\ 119454, г. Москва, проспект Вернадского, 76
}

Данная статья посвящена рассмотрению важнейших элементов функционирования бизнес-инкубаторов, как части инновационной экосистемы, и их роли в развитии предпринимательства. В статье представлены результаты первого и второго комплексного исследования рынка бизнес-инкубаторства России, проведенных Фондом развития инноваций и бизнес-инкубаторства МГИМО в 2012 и 2016 гг. Исследования включали в себя глубинные интервью и анкетирование более 70 директоров российских бизнес-инкубаторов. В опрос вошли следующие блоки: оценка состояния предпринимательского климата в регионе присутствия, общая характеристика деятельности БИ, показатели эффективности БИ, предоставляемые услуги для резидентов, характеристика руководства БИ, финансовые аспекты функционирования БИ.

Ключевые слова: экосистема, предпринимательство, бизнес-инкубаторы, стартапы, менторы, предпосевная и посевная стадии, венчурное финансирование.

\section{Часть I}

Вопрос поддержки бизнеса, прежде всего субъектов малого и среднего предпринимательства (МСП), остается в России как никогда актуальным. Несмотря на номинальное существование большого количества специализированных фондов и учреждений, реализующих различные программы и проекты в сфере поддержки предпринимательства, практика показывает, что представители МСП по-прежнему невысоко оценивают степень благоприятности предпринимательской среды в своем регионе (в среднем 3,64 балла из 5) [1].

В настоящее время представителями государственных учреждений и ведомств нередко озвучивается мнение, что созданная в 2000-е гг. инфраструктура поддержки МСП устарела и требует реформирования. Так, например, в рамках серии встреч «Upgrade-лаборатория» под эгидой
Минэкономразвития РФ в 2018 г. были сформулированы предложения по «перезагрузке» мер поддержки малого и среднего предпринимательства, в том числе «перезагрузке» бизнес-инкубаторов [2]. Следует признать, что выдвигаемые предложения в целом рациональны и отвечают требованиям современного рынка, однако они не носят комплексный и взаимоувязанный характер - в том смысле, что не преследуют цели формирования единой самодостаточной системы (или экосистемы) предпринимательства (например, на уровне регионов), что заведомо снижает их эффективность.

Термин «экосистема» применительно к экономическим и общественным процессам стал использоваться в конце 1990-х гг. Так, в 1996 г. Дж.Ф. Мур предложил понятие предпринимательской экосистемы [3], включающей в себя компании и субъекты их микросреды: постав- 
щиков и контрагентов, рыночных посредников, потребителей и даже конкурентов. В экономике определяющей особенностью экосистемы, как и в естественных науках, является взаимная дополняемость ее элементов, позволяющая им совместно более эффективно достигать общих целей либо получать больший результат при неизменных затратах.

Соответственно, экосистемой инноваций, или инновационной экосистемой (ИЭС), можно называть среду, образованную непосредственно участниками инновационного процесса, в которой протекает их взаимодействие, направленное на создание и развитие инноваций [4, с.17]. К основным свойствам ИЭС можно отнести высокую степень самоорганизации и адаптивности к окружающей среде, децентрализованный способ принятия решений, коэволюция субъектов и взаимодополняемость имеющихся у них ресурсов (знаний, компетенций, финансовых ресурсов и т.д.).

Ключевыми элементами инновационной экосистемы являются: (1) предпринимательство (крупный бизнес, МСП, инновационные стартапы); (2) инфраструктура поддержки предпринимательства; (3) научная сфера (НИИ, ВУЗы); (4) рынок венчурных инвестиций (венчурные фонды, индивидуальные инветоры), а на этапе становления ИЭС еще и (5) государство (органы власти, институты развития). Для успешного функционирования ИЭС важно наличие в рассматриваемом регионе не только всех перечисленных субъектов, но и отлаженной системы горизонтальных коммуникаций между ними, и в формировании именно такой сети и состоит задача государства.

Некоторые исследователи выделяют также термин инновационная среда, характеризуя его как совокупность сложившихся за определенное время условий, содействующих или противодействующих целям ИЭС [5]. Такие условия включают не только объективно существующие региональные особенности, такие как природно-географические характеристики, удаленность от крупных инновационных центров, предпринимательская культура, характер восприятия инноваций и др., но и принимаемые органами власти законодательные акты и инициативы. Последние должны носить комплексный характер и учитывать специфику экономического развития региона.

Взаимоотношения внутри экосистемы ин- новаций базируются на принципах взаимной дополняемости ресурсов и взаимной выгоды, в связи с чем можно выделить функции и желаемые результаты каждого из обозначенных субъектов (табл. 1). Немаловажно отметить, что успешность в достижении этих результатов напрямую зависит от эффективности функционирования всей экосистемы в целом и от качества выполнения упоминавшейся ранее главной задачи ИЭС - создания и развития инноваций.

В контексте вышесказанного интересно проанализировать последние изменения и текущее состояние сферы бизнес-инкубаторства в российской экономике. С точки зрения состава ИЭС, бизнес-инкубаторы, равно как и технопарки, бизнес-акселераторы и широкий спектр сервисных компаний, предоставляющих адаптированные под нужды МСП услуги, относятся к инфраструктуре поддержки предпринимательства [4, С. 21-23]. Иными словами, бизнес-инкубаторы это лишь часть одной из подсистем ИЭС. Тем не менее, следует отметить особую роль, которую играют бизнес-инкубаторы в развитии малого инновационного бизнеса, поскольку именно они становятся отправной точкой в становлении начинающих предпринимателей, а также зачастую несут большую социальную нагрузку в своем регионе, вовлекая в экосистему новые сообщества и социальные группы.

Бизнес-инкубатор - организация, задачей которой является поддержка новых малых предприятий и предпринимателей, которые в силу отсутствия финансовых ресурсов, нехватки опыта и (или) квалификации не имеют возможности реализовывать свои проекты вне бизнес-инкубатора [6]. Первые бизнес-инкубаторы появились в середине XX в. в Великобритании и США, а в России в начале 1990-х гг., получив при этом особую популярность в середине 2000-х гг. (пик по количеству вновь открывшихся бизнес-инкубаторов пришелся на 2009 г.). С тех пор российский рынок бизнес-инкубаторства претерпел ряд изменений как количественного, так и качественного характера, которые можно заметить при сравнении результатов двух комплексных исследований, проведенных в 2012 и 2017 гг.

Чтобы оценить масштаб деятельности бизнес-инкубаторов во всем мире, следует обратиться к статистике Международной ассоциации бизнес-инноваций [7] (InBIA, США), которая до смены названия в 2015 г. фокусировала свою деятельность исключительно на бизнес-инку- 
Таблица 1. Функции и желаемый результат (выгоды) различных субъектов инновационной экосистемы

\begin{tabular}{|c|c|c|c|}
\hline № & Субъект & Функции & Желаемый результат \\
\hline 1 & $\begin{array}{l}\text { Малый инновационный } \\
\text { бизнес, МСП }\end{array}$ & $\begin{array}{l}\text { Реализация завершающего этапа коммер- } \\
\text { циализации инноваций; создание рабочих } \\
\text { мест, в том числе для студентов и выпуск- } \\
\text { ников ВУЗов }\end{array}$ & $\begin{array}{l}\text { Получение знаний и компетен- } \\
\text { ций, привлечение финансовых } \\
\text { ресурсов, расширение команды и } \\
\text { сети контактов, коммерциализа- } \\
\text { ция бизнес-идей, масштабирова- } \\
\text { ние проектов }\end{array}$ \\
\hline 2 & $\begin{array}{l}\text { Корпорации, крупный } \\
\text { бизнес }\end{array}$ & $\begin{array}{l}\text { Главный «заказчик» в ИЭС: предъявляют } \\
\text { спрос на инновационную продукцию, но- } \\
\text { вые технологии и научные исследования; } \\
\text { создание рабочих мест }\end{array}$ & $\begin{array}{l}\text { Усовершенствование продуктов } \\
\text { и сервисов за счет внедрения } \\
\text { инноваций }\end{array}$ \\
\hline 3 & $\begin{array}{l}\text { Инфраструктура } \\
\text { поддержки }\end{array}$ & $\begin{array}{l}\text { Поддержка стартапов на различных } \\
\text { стадиях развития; экспертиза проектов; } \\
\text { предоставление услуг, адаптированных } \\
\text { под нужды начинающего бизнеса; состы- } \\
\text { ковка стартап-проектов с отраслевыми } \\
\text { экспертами, менторами, инвесторами и } \\
\text { бизнес-ангелами } \\
\end{array}$ & $\begin{array}{l}\text { Реализация государственной } \\
\text { политики по поддержке МСП; } \\
\text { извлечение прибыли от предо- } \\
\text { ставления услуг }\end{array}$ \\
\hline 4 & Научная сфера, ВУЗы & $\begin{array}{l}\text { Производство знаний; предоставляют } \\
\text { остальным субъектам ИЭС услуги по } \\
\text { научно-технической экспертизе и консал- } \\
\text { тингу; осуществляют подготовку инже- } \\
\text { нерно-технических кадров, а также специ- } \\
\text { алистов в области экономики и права }\end{array}$ & $\begin{array}{l}\text { Профориентация и трудоустрой- } \\
\text { ство студентов и выпускников; } \\
\text { повышение уровня практической } \\
\text { ориентации образования; доход } \\
\text { от платных услуг }\end{array}$ \\
\hline 5 & Венчурный рынок & $\begin{array}{l}\text { Экспертная оценка и финансирование } \\
\text { высокорисковых проектов }\end{array}$ & $\begin{array}{l}\text { Получение сверхприбыли от } \\
\text { успешно реализованных иннова- } \\
\text { ционных проектов }\end{array}$ \\
\hline 6 & Государство & $\begin{array}{l}\text { Субсидирование деятельности некоторых } \\
\text { субъектов ИЭС (в частности, бизнес-инку- } \\
\text { баторов и технопарков); стимулирование } \\
\text { появлению в регионах всех необходимых } \\
\text { элементов экосистемы инноваций и свя- } \\
\text { зей между ними }\end{array}$ & $\begin{array}{l}\text { Повышение инвестиционной } \\
\text { привлекательности националь- } \\
\text { ной или региональной эконо- } \\
\text { мики; увеличение налоговых } \\
\text { поступлений; создание рабочих } \\
\text { мест; решение ряда социальных } \\
\text { проблем }\end{array}$ \\
\hline
\end{tabular}

Источник. Составлено авторами.

баторстве, а в настоящее время стремится охватить и другие элементы предпринимательской экосистемы. По данным InBIA, по состоянию на конец 2018 г. в мире насчитывается порядка 12 тыс. бизнес-инкубаторов, 93\% из которых относятся к категории неприбыльных. Наиболее часто бизнес-инкубаторы создаются в целях реализации государственной политики по поддержке МСП и решения каких-либо социально-экономических проблем соответствующего региона. Так, в США 84\% бизнес-инкубаторов открываются с целью создания новых рабочих мест, однако задачи могут быть и иными: стимулирование предпринимательской активности и формирование предпринимательской культуры в регионе, активизация процесса коммерциализации инноваций и т.д.

Бизнес-инкубаторы создаются не только обособленно, но и при ВУЗах, а также при технопарках. В первом случае бизнес-инкубаторы способствуют процессу профориентации и трудоустройства студентов, параллельно повышая степень практической ориентации образовательного процесса, а во втором позволяют технопаркам расширить спектр предоставляемых услуг для существующих клиентов, а с другой стороны привлекать новые виды начинающего бизнеса, которые впоследствии будут становиться клиентами самого технопарка. По данным UBI Global, в 2018 г. в мире насчитывалось около 1100 университетских бизнес-инкубаторов [8] (без учета бизнес-акселераторов), что составляет примерно 9\% от общего числа инкубаторов. Более половины бизнес-инкубаторов (52\%) располагаются в промышленных зонах.

Среди наиболее популярных отраслей, в которых развиваются резиденты бизнес-инкубаторов, можно отметить информационные технологии (стартапы из этой сферы присутствуют в 54\% инкубаторах по всему миру), сфера услуг 
(44\%), производство (40\%), биотехнологии (33\%). Вместе с тем менее половины бизнес-инкубаторов имеют какую-либо отраслевую специализацию, являясь, таким образом, смешанными. 39\% инкубаторов специализируются на технологических стартапах и лишь 1\% - на стартапах в сфере услуг.

Численность персонала бизнес-инкубатора в среднем составляет 12 человек, а средняя площадь - 3700 кв.м, при этом загрузка помещений, сдаваемых в аренду резидентам и якорным арендаторам, на уровне 80\% [9]. Следует отметить, что предоставление рабочего места и аренда на льготных условиях по-прежнему наряду с помощью в составлении бизнес-плана входит в число наиболее востребованных сервисов бизнес-инкубатора - эти два вида услуг предоставляют 96\% инкубаторов по всему миру. Среди других популярных сервисов следует выделить маркетинговое консультирование (90\%), бухгалтерский и управленческий учет (84\%), услуги администрирования (81\%), помощь в получении банковских кредитов и привлечение частных инвесторов (79\%), предоставление гарантий для банков (78\%), помощь в создании презентаций (77\%) и обеспечение связи с ВУЗами (73\%) [7].

В среднем на один бизнес-инкубатор приходится 35 резидентов и 3-4 якорных арендатора, хотя общий годовой «поток» МСП, которых обслуживает инкубатор (но которые не присутствуют в нем физически в качестве постоянных резидентов) значительно больше -141 . В среднем в год при поддержке бизнес-инкубатора начинающие предприниматели составляют около 72 бизнес-планов и получают 2 патента. Средняя длительность прохождения программы бизнес-инкубаторства стартапами составляет 30 месяцев, при этом подавляющее большинство из них покидают бизнес-инкубатор либо по достижении безубыточности (что нередко является одним из критериев завершения программы), либо из-за необходимости расширения рабочего пространства.

Среднегодовые операционные расходы бизнес-инкубатора составляют 518 тыс. долл. США. Большая часть этих денег уходит на поддержание инфраструктуры, а также на заработную плату. Несмотря на то, что помещения сдаются клиентам в аренду на льготных условиях, именно рентные платежи составляют почти $60 \%$ доходов бизнес-инкубаторов. В среднем по миру государственные субсидии покрывают около 15\% издержек инкубаторов, однако важно понимать, что этот показатель может сильно отличаться в некоторых регионах и доходить до $40 \%$. Более детально структура расходов и доходов инкубаторов отображена на рисунках 1 и 2 .

Говоря о мировых тенденциях в сфере бизнес-инкубаторства, стоит отметить, что в последние годы значительно возросло количество видов бизнес-инкубаторов. Так, если в середине 2000-х гг. появился особый вид коммерческого бизнес-инкубатора - бизнес-акселератор,- то сегодня можно говорить о куда более сложной классификации. Последнее обусловлено тем, что количество бизнес-инкубаторов по всему миру в целом достигло своего пика и сейчас происходит адаптация сервисов под более узкие запросы клиентов. Для удобства сравнения некоторые типы бизнес-инкубаторов занесены в табл. 2.

Несложно заметить ключевые отличия бизнес-инкубаторов от акселераторов: хотя и те и другие оставляют за собой право проводить конкурсный отбор на участие в программе, биз-

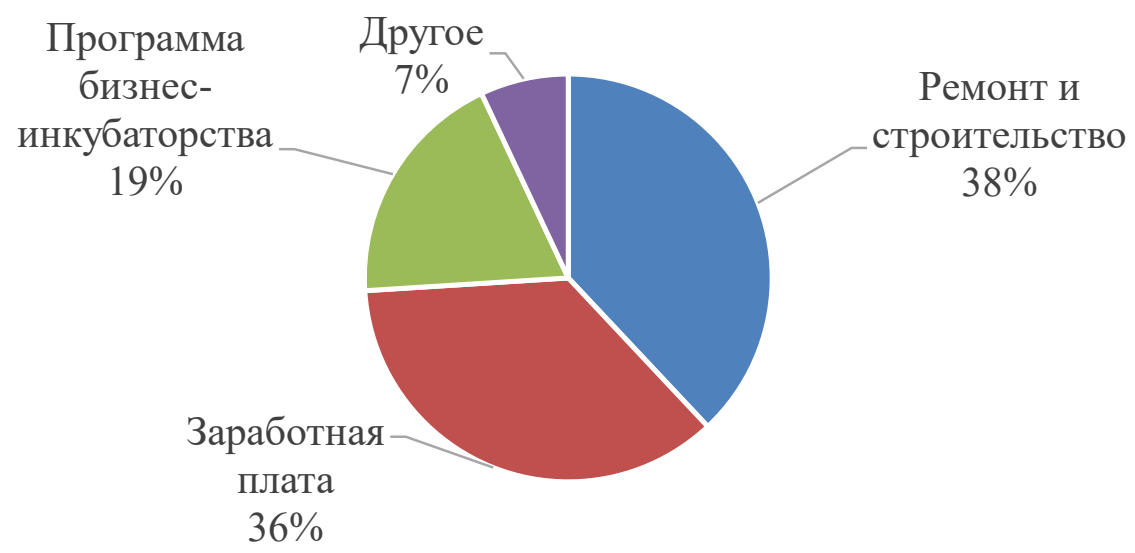

Рис 1. Усредненная структура расходов бизнес-инкубаторов в мире Источник. Составлено авторами по данным InBIA. http://inbia.org. 


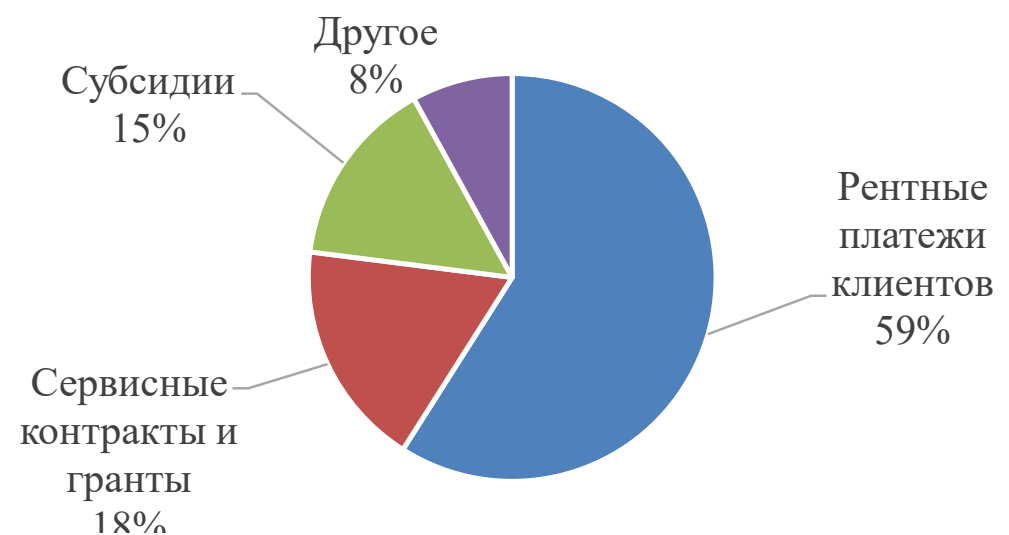

Рис 2. Усредненная структура доходов бизнес-инкубаторов в мире Источник. Составлено авторами по данным InBIA. http://inbia.org

Таблица 2. Сравнение различных видов бизнес-инкубатора

\begin{tabular}{|c|c|c|c|c|c|c|}
\hline Вид / Критерий & 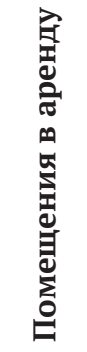 & 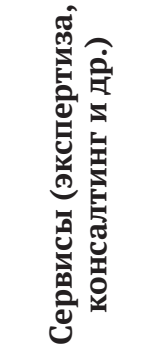 & 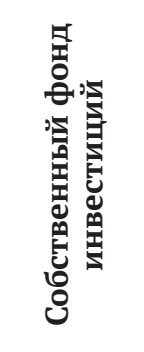 & 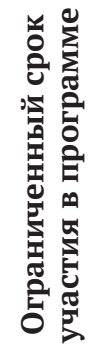 & 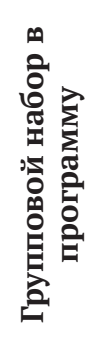 & 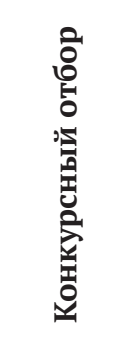 \\
\hline Бизнес-инкубатор & Есть & Есть & Нет & Нет & Нет & Да \\
\hline Бизнес-акселератор & Есть & Есть & Есть & Да & Да & Да \\
\hline Преакселератор & Нет & Есть & Нет & Да & Да & Да \\
\hline Виртуальный инкубатор & Нет & Есть & Нет & Нет & Нет & Да/нет \\
\hline Виртуальный акселератор & Нет & Есть & Есть/нет & Да & Да & Да \\
\hline Коворкинг & Есть & Есть/нет & Нет & Нет & Нет & Нет \\
\hline Мейкерспейс & Есть & Есть/нет & Нет & Нет & Нет & Нет \\
\hline
\end{tabular}

Источник: Составлено авторами.

нес-акселераторы в большей степени нацелены на проведение ограниченных по срокам программ акселерации, предполагающих помимо предоставления базовых услуг по развитию бизнеса еще и инвестирование в стартапы из собственного венчурного фонда.

Преакселератором называют структуру, в которой проекты доводят до уровня, необходимого для получения инвестиций, то есть готовят к дальнейшему участию в программе акселерации. Неудивительно, что преакселераторы часто создаются при бизнес-акселераторах. В литературе можно встретить еще одно понятие - преинкубатор, однако авторы считают, что оно лишено смысла, так как специально готовить проекты для прохождения в программу бизнес-инкубатора, в отличие от акселерационной программы, как правило, не нужно. Исключение составляют доинкубационные сервисы (например, помощь в поиске потенциально успешной бизнес-идеи, составлении концепции бизнеса), однако их обычно предоставляют сами бизнес-инкубаторы. Иногда «преинкубатором» называют предпринимательские курсы для школьников.

Еще одной тенденцией является создание виртуальных инкубаторов и акселераторов, оказывающих услуги дистанционно. В числе основных преимуществ отсутствие территориальной привязки к какому-либо региону, меньшие издержки, а в случае виртуальных инкубаторов работа с проектами на самых ранних стадиях их развития (например, на стадии идеи). Точное количество таких структур установить достаточно сложно, однако по некоторым оценкам в 
мире их насчитывается несколько сотен.

Строго говоря, коворкинг и мейкерспейс" (makerspace, дословно «мастерская») нельзя в полной мере считать разновидностями бизнес-инкубатора, так как они в большинстве случаев не предоставляют ряд важных услуг, определяющих суть инкубатора как инструмента поддержки МСП. Оба формата основаны на использовании общей инфраструктуры и совместной работе предпринимателей и/или творческих лиц, в ходе которой они обмениваются опытом, знаниями и компетенциями, формируют смешанные команды, разрабатывают новые продукты и услуги. Бесспорно, все эти аспекты присущи деятельности и классических инкубаторов, в связи с чем, по всей видимости, ряд исследователей ставят коворкинги и мейкерспейсы в один ряд с бизнес-инкубаторами.

Подводя промежуточный итог, следует отметить, что более чем за полвека своего существования бизнес-инкубатор в целом показал себя как эффективный инструмент поддержки МСП, о чем свидетельствует статистика: $87 \%$ стартап-проектов, успешно завершивших программу бизнес-инкубаторства, «живут» более 5 лет, в то время как выживаемость инновационных проектов, запущенных вне бизнес-инкубаторов, составляет лишь 60\%. Среднее количество созданных рабочих мест из расчета на одного резидента бизнес-инкубатора равно 4,6 [9]. Учитывая ранее озвученную цифру по среднему числу резидентов, можно оценить общую среднегодовую долю инкубаторов в численности занятого населения примерно в 2 млн. человек (что не учитывает число занятых в тех компаниях, которые уже вышли из бизнес-инкубаторов в «свободное плавание»). Кроме того, по расчетам InBIA, в США каждый 1 долл. субсидий, вложенный в программу бизнес-инкубирования стартапов, впоследствии приносит 30 долл. налогов.

\section{(окончание Части I)}

\section{Библиографический список}

1. Второе всероссийское исследование рынка бизнес-инкубаторства. Фонд развития инноваций и бизнес-инкубаторства, 2017. С. 5. http://www.ifbi.ru/research

2. Перезагрузка мер поддержки малого и среднего предпринимательства. Трек: предложения по перезагрузке бизнес-инкубаторов. Upgrade-лаборатория при Минэкономразвития РФ, 2018. http://www.upgradelab.ru/ page-item8.html

3. Moore J.F. The Death of Competition: Leadership and Strategy in the Age of Business Ecosystems. N.Y.: Harper Business, 1997. P. 6-7.

4. Хотящева О.М. Инновационный менеджмент: учебник и практикум для академического бакалавриата / О.М. Хотяшева, М.А. Слесарев. - 3-е изд., перераб. и доп.-М.: Издательство Юрайт, 2017.

5. Райхлина А.В. Формирование инновационной среды региона как важнейшее условие эффективной инновационной деятельности // Интернет-журнал «НАУКОВЕДЕНИЕ» Том 9, № 4 (2017).

6. Конина Н.Ю., Ноздрева Р.Б., Буренин В.А. и др. Современные проблемы менеджмента, маркетинга и предпринимательства: монография. Москва. 2018. С. 485.

7. International Business Innovation Association. http://inbia.org

8. The UBI World Benchmark Study 2017-2018 of University-linked Business Incubators \& Accelerators.

9. Mustafa Toruna, Laura Peconicka, Vinicius Sobreiroa, Herbert Kimuraa, Josep Pique. Assessing business incubation: A review on benchmarking // International Journal of Innovation Studies Vol. 2, Issue 3, September 2018. C. 96.

Поступила в редакцию 31.12.2018

\footnotetext{
* Мейкерспейс - публичное пространство, позволяющее пользоваться общей инфраструктурой (рабочие места, оборудование для прототипирования) и общаться с единомышленниками. Нередко мейкерспейсы не являются самостоятельными организациями и создаются по частной инициативе в подвалах и пустующих помещениях (например, университетов), однако наиболее продвинутые предоставляют качественные сервисы и иногда имеют полноценные учебные центры.
} 